\title{
Atmospheric science encrypted into the epic Raamaayana - A novel perspective
}

\author{
${ }^{\mathbb{m}}$ Vandeep K, ${ }^{2}$ Krishnaiah M \\ Department of Physics, Sri Venkateswara University, Tirupati, Andhra Pradesh-517502, India \\ 'vanadeep303@gmail.com, 2profkrishnaiah.m@gmail.com
}

\begin{abstract}
Ancient Indian Sciences are embedded in Vedas, Puraanas, Epics and Classics. It has been formulated as interesting and dramatic narratives for laymen, while for intellectuals, it is encrypted science. Scientific concepts occur as scattered intermittent episodes during the course of the main storyline of ancient Indian texts. A brief background of atmospheric science during the Vedic period has been provided at the outset. This prompted the post - Vedic scholars like Aarya Bhatta, Varaaha Mihira and others to compile and compose treatises like the Aarya Bhattiyam, Brihat Samhita, etc, that were dedicated to Sciences exclusively. Among all the ancient Indian texts and scriptures, the Raamaayana of Sage Vaalmeeki, the first classic and epic (AadiKaavyam) of the world, commands a unique status of its own in terms of its poetic, aesthetic, linguistic and narrative prowess. In addition to this, it enshrines many sciences mystically. Among all the sciences, atmospheric science or meteorology has a unique relation with Raamaayana. Hence, the principal aim of the present article is to decode and decipher some of the valuable meteorological principles suggested in this epic, by relating them to modern atmospheric science. The various characters in the epic like Raama, Lakshmana, Seetha, Hanumaan, Raavana and others, have been shown to possess a striking relationship with entities of nature, especially atmosphere.Various incidents and episodes in Raamaayana signify several phenomena that occur in the atmosphere, which have been explained in detail in the present article. This would provide significant insights into the depths of Ancient Indian Science, especially meteorology, right from the times of antiquity.
\end{abstract}

Keywords: Atmospheric Science, Raamaayana, Ancient Indian Science.

\section{Introduction and Background}

It did not take much time for the Vedic Rishis (sages) to realize that the orderly functioning of Sun God and the Gods (forces of nature) responsible for the atmospheric phenomena, especially rainfall, was very essential for their very existence and then their prosperity (Vanadeep et al., 2012). From the stage of merely offering prayers, they passed on to the next phase of speculating about the origin of the solar system and of life on earth. In these speculations, they struck at one important concept namely that the Sun and the stars should be constantly fed with some food which is of divine origin and which maintains their brightness and therefore is responsible for their being immortal. The yagnya concept of Aryans has its origin in this principle of feeding of Agni with food (Soma) i.e the offering of Soma in Agni, is perhaps the best definition of yagnya. According to the Vedic seers, the entire universe is created and sustained on the Agni - Soma interaction principle. Agni is referred to as Annaada (eater of food) and Soma as Anna (food). In the Vedas the milky way in the high heavens was identified with Somaand is called 'Soma dhaara', the stream of Soma. This white substance encompassing the upper heavens serves as food to the burning stars and the Sun and makes them shine. They recognized a three-fold existence for Soma viz., 1. Soma dhaara (Milky Way in the heavens), 2.Soma, the moon and 3.Soma juice, which is extracted from the Soma plant. A careful study of relevant passages in the Vedas reveals that the latter two are only replicas (pratikriti) of the Soma substance, which forms food for Agni; because of which creation proceeds. Agni and Soma exist initially in the shapeless form (rita) and when a centre of creation appears, rita Soma feeds rita Agni and an object of creation comes into existence which is termed 'Satyam' that has a definite shape as opposed to the shapeless rita state. In fact, whether it is the birth of the solar system or the occurrence of seasons and rainfall, or the birth of the child or plant, the process at work is yagnya in which a substance of the Soma category is absorbed or consumed by or is in intercourse with a substance of the Agni category.

Hence, the heat and light generated and emitted by the Sun and the Stars is due to the 'Agni' quality in the stars. This is sustained by gases like Hydrogen, Helium etc., which form the food and fuel for the burning of a star. Hence, these gases (or) air/wind in general belong to the category of 'Soma'.

The Vedic seers explained the occurrence of the various seasons in terms of Agni-Soma interaction. The northern side is the seat of heaven and the earth is to its south. They imagined that Agni in rita form is located to the south and is always moving north. Soma is present in the north and is always moving southwards. This corresponds to Soma coming down and Agni(Parthivaagni) moving upwards. This is with respect to rainy season. Therefore, there is a confrontation between the two and the seasons are produced 
because of either of the two asserting over the other five. Vasantha, Greeshma, Varsha seasons show the assertion of Agni over Soma and reverse takes place during the other three rutus (seasons). The northerly movement of the equatorial trough (which later becomes the monsoon trough) during the three former seasons and the penetration of cold weatherly trough southwards during the latter three seasons are suggested here.

The Aryans living in extreme in the northwest India and quite familiar with the land mass located in the north were also aware that in the south, there was a vast oceanic region providing ample scope for absorption of water by Sun's rays whenever he moves to the south. They imagined that Agni in the rita form is located in the south and always moving towards the north. On the analogy of snow present in the northern latitudes, they imagined Soma to be present in the north and always moving to the south. This corresponds to Agni moving up and Soma coming down in the vertical. There is a constant confrontation between the two and the seasons are produced as a result of either of the two asserting over the other. The dark path that is referred to here is the southward position of the Sun. The rita sadanahere refers to the abode of rita that is Himalayas, near which the Sun attains his northernmost position. That is the position when the Sun turns back his rays and retraces his path. With this background if we examine this concept, it probably suggests that humid air moving northwards gets deflected near the foot of the Himalayas and pours down rain and drenches the earth (Ramanathan, 1991).

Eight types of rainfall have been described in the Vedas. They are: Jinvaraavrita; produced by east wind;

Ugraraavrita; raining with winds; Bhaumaravrita; thundering and raining; Tveshaaraavrita; thundering without lightning, with lightning, raining; Poortiraavrita; raining overnight; Shrutaraavrita; famed as raining much; Viraadaavrita; raining while the Sun shines; Bhooparavrita; thundering, lightning, raining.

It is also clear that they recognized the appearance of moist easterlies bringing monsoon and the simultaneous disappearance of the westerlies at the time of commencement of rains during the rainy season. The absorption of moisture from the oceans and the movement of moist winds northwards to give rain in their region at the time of the Sun retracing his path after reaching the extreme northern position, were also recognized by them.

The Soma reaching the atmosphere mixes with the water vapour and Indra aided by Parjanya and Purovaata (easterlies) brings rains to the region of settlement of the Aryans. The Vritra, Vaala, Ahi, Namuchirepresentasuraor negative forces that have been mentioned earlier.

The Indra-Vritra confrontation in the hilly regions adjoining the region of the settlement of the Aryans is beautifully described in the Sloka 32 of the first mandala of Rigveda.

The Aryans were familiar with various forms of existence of water at low temperature, like fog, mist, dew, snow that finally becomes fern, ice and glaciers. In post-Vedic Sanskrit literature, we have words like Dhoomika or kujhati(thick fog) avasyaaya (dew), thushaara(frost), hima (snow) etc. It is very probable that by the first-born of Ahis, low cloud or thick fog is meant.

"With his vast destroying thunderbolt Indra struck the overpowering but mutilated Vrtra. As the trunks of trees are felled by the axe, so lies Ahi prostrate on earth".

Severe thunderstorm activity sometimes disturbs the huge snow pilings, which come down in huge blocks of ice.

Widespread avalanche activity also takes place whenever there is sudden warming of the upper air. In such cases, complete disarray of the snow and ice pack on mountaintops and slopes results in huge chunks of ice and snow coming down sometimes accompanied by landslides. This is what is described here. Sometimes these huge blocks cause landsides on the steep banks of the channels, which are completely blocked as a result, and sometimes their courses are altered. Because of the transport of ice and snow to lower levels, melting increases though the heaping effect restricts the area of exposure to sunlight and tends to decrease the rate of melting.

"Having neither hand nor foot, he defied Indra who struck him with the thunderbolt, upon his mountain-like shoulder; like one emasculated trying to pose, as virile person. Then Vritra, mutilated very badly, slept". Here the shattered blocks of ice and snow lying on the bottom of the slope of mountains are referred. It also denotes the multi-shaped cloud patches which are seen close to the mountains after the thunderstorm activity is over.

"The waters that delight the minds (of men) flow over him recumbent on the earth; as a river bursts through its broken (banks), Ahi has been prostrated beneath the feet of the waters, which Vritra by his might, had obstructed".

The melt-water flowing in the channel completely submerging the ice blocks which are sometimes partially buried in landslides, is described here. A distinction is made here between Vritra and Ahi. We shall comment on this when we see the next ruk.

"Just like the cows blocked by Paani, the waters stood obstructed when they were guarded by Ahi and were under the control of Daasa (Vritra) as though they were his wives. But by slaying Vritra, Indra set open the cave that had confined them".

Here we get some clue to understand the terms Ahi and Vritra. Ahi represents an ice block or big snow chunk or even a glacier. Vritra represents a condition in which water is not allowed to flow out ice pieces. 
The asterisms according to our ancients are distributed in one zodiac in a belt of $48^{\circ}$ with a spread of $24^{\circ}$ on either side of the celestial equator. The planets also move within this belt. Initially there were 28 asterisms. Later, Abhijit, which was assumed located partly in Uttaraashada and partly in Sravana, was dropped leaving 27 asterisms covering the Zodiac. In order to identify the nakshatrams, our ancients first developed the idea of groups of stars having shapes of animals, birds, men etc. In each group, they identified one bright star, which was called yogataara. In order to facilitate the location of these stars, the astronomers then developed the idea of separate paths in the celestial sphere in which these stars are distributed. They imagined three broad belts parallel to the celestial equator and these were named Iravata, Jaradgava and Vaisvaanara. Vaisvaanarais is on the southern side of the equator, Iravata on the southern side and, Jaradgava in the middle. Each of these three broad belts was further sub divided into three secondary belts (vithis) so that there were nine Vithis, three on the northern side, three on the southern side and three in the middle. These nine Vithis, from north to south, have the following names:1) Naaga 2) Gaja 3) Iravata on the northern side 4) Vrisha 5) Go 6) Jaradgava in the middle 7) Mriga 8) Aja 9) Vaisvaanara on the southern side.

It is interesting to note that for a man located outside these belts in the northern hemisphere, the span of these belts above the horizon would appear smaller and smaller as one proceeds southwards and the names of the belts are quite suggestive of this diminution. In fact seven horses which the sun rides on, are nothing but the seven tracks of the sun, three on the southern side, three on the northern side and one in the middle (along the celestial equator). They are incorporated in the Vedas as seven metres (Chandas) Gayatri (24 syllables) being associated with the southernmost track and Jagati (48 syllables) being associated with northernmost track. Brihati (36 syllables) is the track along the celestial equator. The movement of the moon across the sky is not only associated with one yogatara every day but also with each of these belts. In other words, the nakshatras are distributed in the nine Vithis, three in each. If we see these nakshatras in the sky and follow them in succession i.e., in the order Asvini, Bharani etc., we get a pattern resembling a moving serpent with them. It is for this reason the collection of these stars is sometimes called 'Nakshatrika Sarpa'. We may also say that the moon moves through them like a serpent. The movement of Sun and Moon among stars resembles two serpents intertwined to each other (described in chapter 1). This double helical inter-coiling of the serpents about a fixed entity also represents the electron, proton and neutron in an atom. During the western disturbances period, it was conceived that the formation of cloud foetuses takes place as a result of injection of Soma from the north-a process of fertilization. That is why during this period, a soft wind from the north is considered as a favourable symptom. The northern region is the abode of Soma (snow) and the south, the seat of Agni, so that the southward movement of Soma and the northward movement of Agni are essential for the functioning of the cycle of rtus or seasons, which are caused by the interaction of Soma and Agni. To put in a more direct way, the western disturbance activity pushing Agni (Sun) to the south and the northward movement of the Sun pushing Soma (snow) to the north are essential for the occurrence of monsoon rains. Keeping in mind the above ideas, the post-Vedic scholars believed that, whenever the Moon moves in a northerly track or is restored to a northerly track, conditions are favourable for the formation of healthy rain fetuses. Whenever moon moves in a southerly track with Sun (Agni) on her northern side, or whenever a condition of Soma being overpowered by Agni is created, it favours abortion of rain fetuses if the fetuses are not fully developed and a healthy delivery of rainfall if the fetuses have gone through their full period of growth.

It is important to note here that according to the Vedic seers conception takes place during the winter period when the snow accumulation increases. To be in harmony with this, they believed that the moon plays a favourable role in the formation of rain fetuses when she is in the waxing stage. During the summer months when the snow accumulation is depleted, the Moon's waning stage happens to coincide with the delivery of rainfall or abortion if the rain fetuses are not fully developed. The observations that rainfall takes place during certain months of the year only and during this period the Sun passes through the same stars every year (neglecting precession effects, of course) led the post-vedic scholars to involve the stars without difficulty in the prediction of rainfall process. The monsoon completely withdraws from northwest India in the beginning of the month of Kaartika (October-November). The days are characterized by clear skies in the region and temperatures show a falling trend especially in the nights.

In the month of Maargasira (November-December), the western disturbance activity slowly picks up and we get one or two disturbances, which normally are mild to moderate. The anticyclone at the lower levels over northwest Pakistan and adjoining Iran begins to build up. Because of the prolonged absence of rain, haze in the sky increases. The temperatures have not yet fallen appreciably.

In the month of Pausha (December-January), frequency of western disturbance increases and temperatures fall sharply. The plains sometimes get appreciable rain and behind the disturbances, the sky clears and the haze decreases.

In the month of Maagha (January - February) the western disturbance activity reaches a peak sometimes giving rise to thick fog or frost, especially whenever the skies clear in the night after the passage of western disturbance. The foggy conditions during the day keep the maximum of the day temperatures, at the lowest of the year. 
In the month of Phaalguna (February-March) westerlies assert themselves in the region. Haze, which cleared during peak western disturbance activity, again increases.

In the month Chaitra (March - April) westerlies continue, temperatures slowly build up and the first thunderstorms occur and decrease the haze.

In the month of Vaisaakha (April - May) the temperatures increase, skies are clear except when there are thunderstorms, which gain strength as summer advances.

One of the interesting observations of our ancients was that too much rain during the period of initial growth of the rain fetuses results in poor rainfall at the time of delivery. They imagined that rain fetuses are destroyed (garbhasraava) if there is too much rain during the time of their early growth period. It was until very recently that it was believed too much western disturbance activity affects the monsoon rainfall of the subsequent season. In fact, the very first forecast of monsoon rainfall issued by Blanford, the first chief of the India Meteorological Department after the successive famines of 1876 and 1877, was based on the negative correlation between snowfall and subsequent monsoon rainfall. It proved to be correct at that time though we know that it is very rare that the monsoon will fail successively for three seasons. (Ramanathan, 1991)

It was also believed by our ancients that hotter the conditions are in the month of Vaisaakha and Jyeshtha (May - June), the better will be the performance of the monsoon. This was also the view of the meteorologists in the early stages of development of forecasting techniques.

Too much rain during the month of Chaitra was considered to spoil a good monsoon High temperature during the pre-monsoon period was imagined to be a good sign for the monsoon rains. These were extremely useful thumb rules for forecasting monsoon rainfall and were practiced by modern meteorologists during the early stages of development of Indian Meteorology. The climatic pattern of the weather during the growth period, Phaalguna-Jyeshtha, was well known to them and any departure from it was considered to affect the normal performance of the monsoon. Considering the fact that long range forecasting of monsoon performance is still on its infancy stage, it can be safely concluded that our ancients had done remarkably well in developing the rules for the same.

The post-Vedic scholars had also carefully observed changing wind direction especially whenever rain occurred due to a moving system. Many rules involving change of wind directions were framed by them. For example, the following rule extracted from Kaadambini obviously refers to a moving system.

"When wind from the north is stopped and wind from the East blows, it portends rain for five days. When wind from the east stops, and wind from the south blows, there will be rain for three more days. When the wind from west is stopped and wind blows from the south-west, the rain decreases". In fact they had such a good weather sense that they were able to foresee the occurrence of heavy rain four or five days ahead, based on wind observations. Furthermore, Varaaha Mihira categorically states that the direction of clouds and winds during the period of pregnancy of clouds is reversed during the period of their conception, i.e. during the rainy season. This assertion demonstrates the prowess of our ancient Indian seers pertaining to atmospheric circulations and dynamics.

Our ancients had studied the seasonal winds that will ensure good monsoon rains and knew which of them were beneficial and harmful in every month or season. Many details of seasonal winds and their effects are available in literature. But unfortunately, unless one can fix the region in which they are applicable, there is the danger of a mix-up of the details pertaining to different regions.

'Abhra' means low spreading clouds. Cumulus clouds seen here and there are called 'Ghana' and clouds covering the sky like a sheet (Stratus type) are called 'Ghata'. 'Meghamaalamanjari' enumerates eighty types of clouds ten each in Mandara, Kailaasa, Kota, Jathara, Sringavera, Paryanta, Himavat and Gandhamaadana mountains. Another classification of the clouds names them Naaga, Parvata, Vrishabha, and Arbuda. The clouds that are found on hill regions during winter giving solid precipitation are said to belong to Diggaja class.

The observations on lightning were used by our ancients for forecasting rainfall as well as for forecasting good or bad days ahead. Given below are some details available in Bhadrabaahu Samhita as an illustration: (Ramanathan, 1991)

- If the sky is cloudy and at that time if lightning is seen in the East and its colour is white or yellow it surely brings rain the next day.

- If there is intense lightning in the East and its colour is red and at the same time if there is wind, there will be only be light rain.

- If lightning of low intensity is accompanied by quick thunder and moving clouds, there will be good rain and sometimes hails occur.

- If the colour of lightning is that of saffron, it will be hot the next day and there will be heavy rain in the afternoon.

- If the sky is filled with blue clouds and it looks dark everywhere and if at that time, there is lightning with blue colour and heavy thundering, there is indication of an approaching storm with strong winds, which will bring rain in three days.

- If there is intense lightning in the north and if the sky is overcast, then, in the morning there will be heavy rain. 
- If the clouds are reddish in colour and if at that time during the day there is lightning, it indicates drought conditions ahead.

'Meghamaalamanjari' gives interesting details about observations on thunder. Thunder heard in the morning brings

immediate rain. If it is heard in the noon, it destroys rain. Thunder heard in the evening brings a lot of rain. If thunder is heard in the previous night and rain follows, it will last for three days. If it is heard at midnight, it will bring very heavy rain and if it is heard towards the end of the night, it will rain for a week. The author also gives forecasts of rain based on the nature of sound of the thunder as heard by us. If it sounds 'Ghuти Ghumu', it portends heavy rain and prosperity. If it sounds ' $k a l a$ pala', it will give only scanty rain. If it sounds ' $D h a, D h a, D h a$ ' it will destroy rain. If an explosive sound is heard, there will be hardships to people. Nevertheless, in all cases whenever thunder is heard and is preceded by lightning, it is considered auspicious.

According to Kautilya, if one-third of the total annual rainfall came from the beginning and ending month of the rainy season, two-thirds in the middle, it augured good crops.

The post-Vedic scholars had also made observations on precipitation in the form of snow in the hilly regions. They knew that thick fog becomes dew when the temperature decreases. Dew was called 'Avasyaaya'. Thick fog was called 'Dhoomika. 'Kujhati' is another name for mist or fog. 'Tushaara' is heavy snowfall. 'Praaleya' is fern and 'Hima' is the general term for the snow. They were also familiar with hail that was called by them as 'Karaka'.

The meteoric showers were objects of intense observation for our ancients. Several types were identified and meanings were attached to them. Fiery skies, dust- borne skies, comets, eclipses, conjunction of planets etc., were also observed by them and interpreted.

(Source- A.S. Ramanthan, Deputy Director-General of Meteorology (Retd), India Meteorological Department (IMD), (1991), Introduction to Kaadambini of Madhusudan Ojha, pp.1-44).

Uma Shankar Dubey (1989) has also carried out commendable work on the ancient science of rains and brought it out in the form of a book 'Praacheena Varshaa Vignyaan'. This deals with the techniques of predicting and forecasting rainfall from Vedic times to medieval times.

\section{Unique Relation of Raamaayana and Atmospheric Science}

Raamaayana can be perceived to be a meteorological treatise in disguise. From this perspective, Raamaayana (the path of Raama) is actually the Suryaayana (the path of Surya (Sun)). During a year, the Sun's path is divided into two: 1) Uttaraayana (Northerly path) 2) Dakshinaayana (Southerly path). Raama's story in Raamaayana starts with his life in Ayodhya and surroundings in North India and then gradually proceeds to South of India and ends with Raama returning to his kingdom in Northern India. This exactly resembles Sun's transit during a year. This is evident from the fact that Raama was born in the Surya vamsam (the dynasty of the Sun). Seetha was described to be the personification of the earth and in Raamaayana, Seetha was born out of earth and has been hailed to be the daughter of Bhoodevi (Mother earth). In the end, Seetha again merges with the Earth. This represents the Earth's tectonic dynamics (since Seetha represents the Indian land which is a part of the entire land mass of the Earth, she is depicted as the daughter of Bhoodevi), wherein landmasses had separated and combined during remote geological eras. Lord Hanumaan is the personification of wind as he is the son of Vaayu Deva (Wind God). Hence, the nomenclature Maaruti is given to him making him the combined personification of different types of winds. The Pavamaana eulogized in the Vedas might have been transformed into Pavana Putra Hanumaana during the period of Raamaayana. The influence of the Sun is felt and imparted by the atmosphere (winds). That is why during the phenomena of solar flares and sun spot cycles, the direct impact is revealed in the form of drastic atmospheric changes. This is the reason why Hanumaan is known as Raamadoota(messenger of Raama), in the same way as atmosphere / wind is the messenger of the Sun. Raavana signifies very dense, dark, thunder clouds arising in the South. The very word 'Raavana' means 'the one who makes a loud noise' as the word 'Raavam' in Sanskrit means 'sound'. Raavana is called "Dasha Vaktra" and "Dasa Greeva" meaning 'the one with 10 mouths (or) 10 voices'. This shows that he makes such a loud noise, which is the basic characteristic of a thundercloud. His kingdom Lanka is situated to the South of India. Therefore, he is a group of dark, dense clouds situated in the southern direction. Ancient Indian meteorologists repeatedly state that the clouds arising in the South do not prove beneficial and auspicious for people. They may result in either drought or deluge. Hence, Raamaayana depicts a phenomenon where there were thick, dense clouds (Raavana), hovering and lingering over the Indian land (Seetha) and made her devoid of Sun's (Raama) light and beneficial rainfall. The war waged by Raama with the help of Hanumaan represents the operation of favourable winds initiated and propelled by Sun's radiation. These winds carry the Sun's insolation effectively and aid in clearance of the destructive clouds over the region. Hanumaan setting Lanka on fire points to this concept. The irrefutable fact that Sun's heat is transmitted by winds has been demonstrated aesthetically in the form of Lord Hanumaan carrying Lord Sri Raama on his shoulders. 
These winds, with the energy of the Sun, made the clouds rain and weakened them by draining away their moisture content and dissolving the clouds ultimately. This attempt of restoration of clear and normal weather conditions over the region by the annihilation of disastrous clouds has been termed the 'Raamaayana war' (Fig.1).

\section{Fig. 1. 'Raamaayana War' could well be perceived as a 'Climatic Battle'.}

(Image Source: www.bollycurry.com)

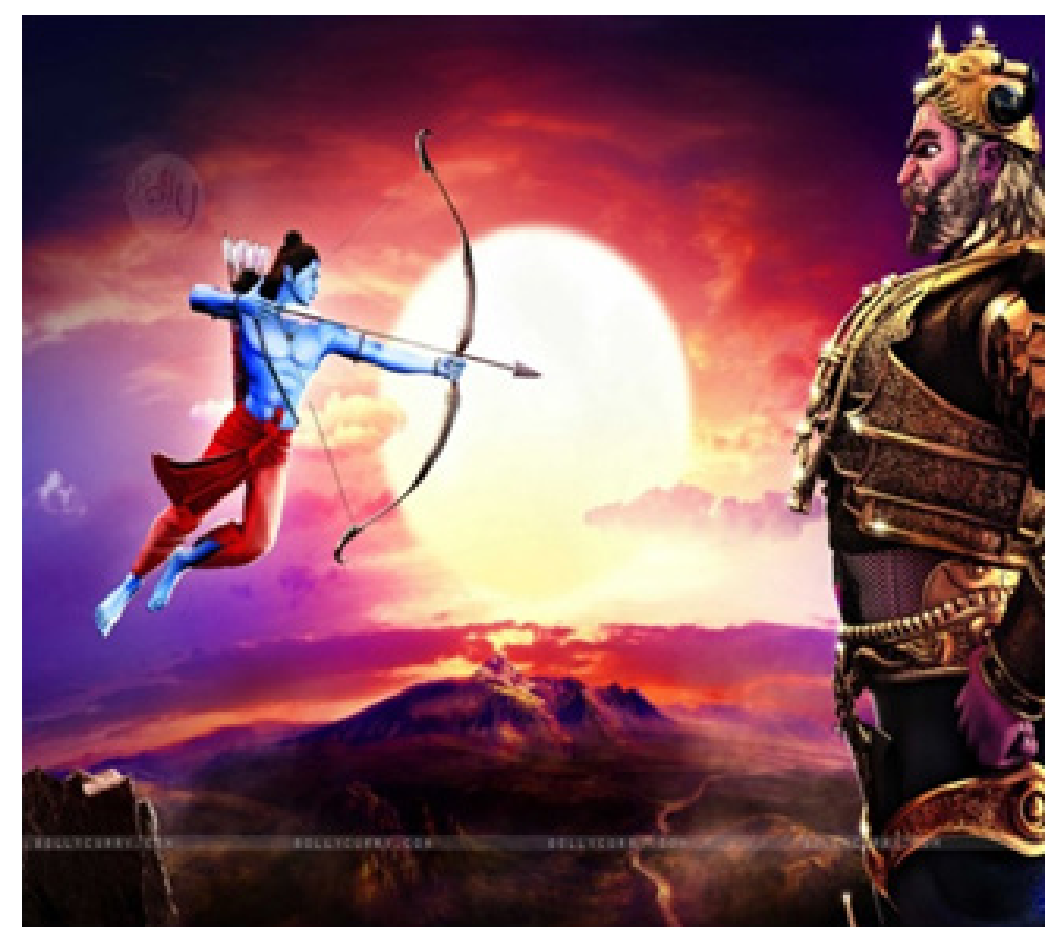

\subsection{Vaali}

Vaali in Raamaayana represents a very strong anti-cyclonic formation, which results in arid conditions. These winds disperse the clouds and cause a surge in temperatures. Hence, Vaali can be described as gale wind that disrupts atmospheric stability (air is called "Gaali" in Telugu). We have already seen in the section that like Vritra and Ahi, 'Vaala' is also a force that disturbs rainfall. Hence, the name 'Vaali' here stands justified. In Vaalmeeki's Raamaayana, Vaali is the son of Lord Indra, who is the overlord of meteorological phenomena. Since such anti-cyclonic gale winds drain away the moisture content, Vaali is said to drain half of his opponents' energy before even the actual confrontation takes place. Vaali is always at bitter strife with Sugreeva, his younger brother, who is the son of the Sun God. 'Su' means good and 'greeva' means 'neck' or 'face'. Hence, Sugreeva represents favourable temperature conditions or beneficial rain clouds that arise from optimal temperature and the subsequent pressure conditions. Vaali had a curse that if he enters the Rushyamooka mountain area, he would perish instantaneously. The meaning of the word 'Rushya' is the one that possesses the quality to move on flow. Mooka in Sanskrit means 'mute'. In Telugu, 'mooka' means a 'group'. In Australian aboriginal language, it means 'flow of waters'. Generally, hilly regions are associated with cogenial weather conditions like moisture-filled winds, optimum temperatures etc. when dry and unsaturated winds approach such hills, they begin to rise and absorb moisture gradually while rising. Gradually, they become saturated, which eventually comes down as precipitation. This is symbolically stated as Vaali's curse involving the Rushya Mooka mountain, which is situated somewhere in the Western Ghats.

Vaali also represents the phenomenon of 'atmospheric inversion' which mainly occurs during winter. During this inversion process, the cold surface of the earth cools the layers of air immediately above it, thereby decreasing their temperature than the overlying layers of air. This prevents the convective mixing of air layers in the atmosphere, resulting in foggy conditions, reduction of visibility, nasal irritation and burning sensation in eyes if the air contains pollutants. There are three types of inversions:

- $\quad$ Radiative Inversion (General condition seen everywhere)

- $\quad$ Subsidence Inversion (Associated with subsiding (anti-cyclonic) layers of air at high pressure; can be seen in mountain regions, valleys, etc.) 
- Double Inversion (When the above two occur simultaneously)

The formation of inversions generally represents stable atmospheric conditions, where there is no possibility of rainfall at all. (For convection and rainfall to occur, unstable and dynamic atmospheric conditions are the prime requisite parameters, where there needs to be ample 'mixing depth' for layers of air). Further, there is an incident in Raamaayana when Raavana approaches Vaali and invites him to battle in which eventually Raavana is defeated badly. This can be explained as the clouds being dispersed and dismantled helter-skelter when they approach a powerful anti-cyclonic formation. This Vaali has been killed by the arrows of Lord Raama, i.e. insolation by the intense rays of the Sun that dissolved this anti-cyclonic formation by inducing a balancing pressure gradient i.e., by creating a low-pressure area, as we know that air always travels from high pressure to low pressure. Vaali and Sugreeva were twins and it has been stated in the epic that it was almost impossible for an on-looker to distinguish between Vaali and Sugreeva. From the atmospheric point of view, Vaali and Sugreeva represent very similar phenomena that are governed totally by temperature and the subsequent pressure (gradient). Hence, the look-alike concept of Vaali and Sugreeva is justified both mythologically and meteorologically.

\subsection{The episode of Ahalya}

The word 'Ahalya' in Sanskrit means 'unploughed' as 'hala' means a 'plough'. This refers to a barren land that has been rendered unfit for cultivation for long. Gautama, the husband of Ahalya represents the entire process of agriculture involving tilling, ploughing etc. The word 'Gau' refers to a bull that represents the activities of farming figuratively. The relation between Indra and Ahalya denotes a period of untimely rains / floods that drained the entire land of its fertility. These made the agriculture come to a standstill and subsequently, the region was abandoned. Such unfavourable climatic conditions prevailed for years together wherein there was no adequate Sunshine incident on the region. Finally, with the arrival of Raama (Sun), Ahalya(the barren land) returned to normalcy with the touch of Raama's feet (Sun's rays). The 'Arunam'in the Rigveda also has this Ahalya episode, which gives an account of the primordial times of earth's evolution. Hence, this entire episode of Ahalya in the Raamaayana is an intricate atmospheric science embedded into intimate story.

\subsection{The Encounter withTaataka}

Sage Viswaamithra (Sun is called 'Mitra' in ancient scriptures) took young Raama and Lakshmana to dense forests for the annihilation of all the demons (asuras). It was said that the forest did not even receive sunlight and appeared grotesque. This forest was said to been infested by a fearsome mighty demoness Taataka which left the entire region deserted. Raama killed the demon and, all the Devas (celestial beings) eulogized Viswaamitra and Raama.

Taataka frustrated and tortured the sages by not allowing them to perform their auspicious and sacrificial yagnyas. The sons of Taataka, Maareecha and Subaahu dumped various impurities like sand, stones, animal remains and other such things into the sacrificial altars. As per meteorology, since Taataka could be a dreadful group of cumulonimbus storm clouds, it is typical of such clouds to possess violent updrafts and downdrafts of air. Sometimes these updrafts lift up various things, animals and other things and when they are weakened, release these objects over that region. Maareecha and Subaahu may be equated to the violent winds (drafts) of the gigantic clouds. Hence, they are described to be the sons of Taataka as such winds are very closely associated with clouds. Hence, the annihilation of Taataka and other demons in Raamaayana suggests the transition of weather conditions and other related phenomena. The incident of Lord Sri Krishna lifting up the Govardhana Giri Mountain when there were incessant rains lashing the region in order to protect the people and animals also portrays a meteorological phenomenon in spirit. Therefore, a thorough and comprehensive study of ancient epics, puraanas etc would certainly equip us with a bountiful fund of atmospheric expertise of those days. Going by the Indra-Vritra confrontation, we know that the asura forces are the conditions, which hinder the normal functioning of weather parameters, and the Deva forces are those which positively facilitate them. This killing of Taataka by Raama signifies the resumption of clear weather conditions over those regions with abundant Sunshine making them inhabitable.

\subsection{The episode of Rushya Sringa}

Sage Rushya Sringa was the son of Sage Vibhaandaka in Raamaayana. The very name 'Rushya Sringa' is noteworthy. The meaning of 'Rushya' means the 'one that possesses the quality of moving or flowing'. 'Sringa' means the 'top of the mountain' It also has another meaning 'fountain of water'. It was said that there were severe drought and famine in the Anga kingdom. Sages had instructed the king Roma Paada (Loma Paada) to invite Rushya Sringa to the kingdom which would augur bountiful rainfall. Rushya Sringa never saw or had any idea of women until then, during his life. Shaanta, the daughter of Dasharatha was sent to him. He was attracted to her and stepped into the kingdom bringing copious and beneficial rains with him. He was married to Shaanta eventually. This shows that Rushya Sringa is analogous to a mountain. The kingdom faced scarcity of rainfall owing to the absence of rain- 
bearing winds. These rain-bearing winds are gentle-moving as they are heavily laden with moisture. Shaanta is a manifestation of such winds, as the word Shaanta means 'calm and peaceful'. Hence, when such winds approach hills / mountains, due to the orographic uplift, they reach their saturation point and rain in the region profusely. This meteorological phenomenon had been codified in the form of this episode.

Moreover, Shaanta is the daughter of king Dasaratha. The meaning of Dasaratha is 'the one whose chariots run in all the ten directions' (four directions, four sub directions, up and down). This applies to both light and wind. Hence, when Raama (Sun) retires to forests on exile, the universal light loses its significance and fades away (the passing away of Dasaratha). If we relate Dasaratha to such generic universal light, then, Raama, who has been identified with Sun, being his son, is justified completely. If Dasaratha is identified with wind, then, Shaanta, (rain- bearing moist winds), which represents one particular category of the wind, is his daughter very convincingly. Thus, the wedding of Shaanta (moist winds) and Rushya Sringa (hill / mountain) produced rainfall, illustrating the concept of orographic rainfall.

Hence, Raamaayana in considerable spirit is an atmospheric treatise elucidating various weather phenomena encountered on the path of the Sun's transit during a year across the Indian subcontinent. The war being the climatic encounter where the enormous army of Vaanaras, especially Lord Hanumaan (favourable winds) under Sugreeva (favourable temperature conditions) lead by Lord Raama(Sun) defeated Raavana (dense and disastrous clouds) and freed Seetha (Indian region) restoring normal climatic conditions over it.

\subsection{Raama and the Sun}

The word 'Raama' means 'the one with whom everyone merges and enjoys and the one who easily attracts everyone' (Ramayati iti Raamaha). The 'Ra' syllable (Beejaaksharam) is called "Agni Beejaaksharam". Agni and Soma are like double helical serpents intertwined (similar to the shape of DNA and the Caduceus) over a manifested substance (Satyam) because initially there were only un-manifested Rita Agni and Rita Soma whose conjunction produces a perceivable manifested entity. In this section, we have already come across the concept that the universe is sustained by Agni-Soma interaction or in other words, the Anna-Annaada relation. Soma is described to be the 'Celestial nectar' (Amrutam) in Vedas, by the consumption of which all the Gods (Atmospheric forces), including the Sun)) gain power and dispense their duties efficiently. Hence, the Sun gives out Agni (fire) and also causes rain (Soma), which sustain the life on the earth like nectar. Both the principles of Agni and Soma thus emanate from the Sun. In the word Soma, when the Agni Beejaaksharam RA is substituted in the place of 'SO, it becomes Raama, which points definitively towards the Sun. In the divine Vishnu Sahasranamam, Lord Vishnu is described to be "Anna Annaada eva cha" ie. 'He (The Almighty) is both Anna and Annaada'. That is why, in Indian tradition, we worship Lord Raama and Lord Soorya (Sun) as the effulgent immaculate personalities of the Almighty himself. Hence, Raama is called Sri Raama Chandra, underlining the concept that the same Soorya (Sun) sustains the day in the form of Agni and the night in the form of Soma. Since Raama (Sun) bestows life and prosperity upon the entire world, Saint-Composers like Thyaagaraaja addressed him as Jagadaanandakaaraka (the cause/bestower of happiness on the Universe). This is the reason why Aadithya Hrudayam (meaning - 'The Heart of the Sun') was taught to Raama to inspire and rejuvenate him on the battlefield.

\subsection{Hanumaan, the disciple of Sun}

Another interesting description that we come across in Raamaayana is that of the teacher-student relation of Sun and Hanumaan.During childhood, Hanumaan was up to the activity of engulfing the Sun, imagining it to be a delicious fruit. Hanumaan, who is the personification of wind, represents the haze, halo, dust storm or even mighty cumulonimbus clouds (the rapidly rising up-drafts of wind) that block the Sun's rays in this context. Moreover, he drives away Raahu, who was fast -approaching to eclipse the Sun. Here, Sage Vaalmeeki described a typical weather phenomenon during an eclipse (many post-vedic scholars do not rule out the possibility of haze and dust storm during the time of eclipse). Even the emergence of sage Vaalmeeki from that termite mound (Valmeekam) is being described as the emergence of Sun from thick fog (Neehaarat Iva Bhaaskaraha). Sage Naarada was believed to have imparted the knowledge of Raamaayana to Sage Vaalmeeki by introducing him to the storyline of the epic briefly and initiating as well as instigating him to author the first epic-cum-classic of world literature (Aadi ithihaasam and Aadikaavyam). Naarada means the 'bestower of waters' as in Sanskrit 'Naara' means 'water' and 'da' means 'to give'. As Vaalmeeki is described as a Sun emerging out of the mist, it can be easily assumed in terms of meteorology that the mist and the other fog shrouding the Sun were cleared and scavenged by the rainfall bestowed by 'Naarada' who represents the clouds / moisture that form the clouds and make them rain. We all know that rainfall has a cleansing action on atmosphere and everything appears to be very clean, clearandbrightafterspellofrainfallasitpurifiestheairandprovideswithanuninterruptedvision. Thereflectedlightfromtheobjectsreachesour eyeswithoutmuchrefraction, diffractionandscattering. Hence, itisnowclearastowhyVaalmeeki(theemergingSun)draftedRaamaayana(The 
Sun's Path).

\subsection{Naaraayana and the Hydrological Cycle}

'Naaraayana' in Sanskrit means 'the path of waters' i.e., it showcases the phenomenon of the life-sustaining hydrological/water cycle. Water on the earth gets evaporated, rises up as water vapour, saturates, forms clouds, which on condensation, rain on the earth and water reaches the surface water bodies and add up to the 'water table' as well. This is the 'path of waters' broadly. This undoubtedly forms the basis of life on the earth. This cycle is represented by Naaraayana, who is worshipped as the 'sustainer' of this 'Universe'. He holds a 'Chakram' in his hand, which denotes this cyclic process of circulation of water (Naara). The Sudarshana represents the light or fire (temperature by insolation) entity, which initiates and promulgates this cycle (Chakra). The 'Shankham' (Conch) in his hand may be taken to be the sound of thunder that is the precursor and principal portent to rainfall. Since a conch is born from the water (seas/oceans), it can be assumed to represent the quality of water on the earth. The sound from the conch is generated through the blowing of wind into it. Hence, this also symbolizes the atmospheric entity, proving that winds are the cause of clouds that produce thunder and rainfall. The mace (Gada) may be taken to be the streaks of thunderbolt (the shape of the mace also resembles that of a bolt) as well as the earth entity and finally, the Lotus (Padmam) in the fourth hand, stands as an ultimate symbolism of blossoming and flourishing of life due to this cycle on the earth. Further, Naaraayana's bow (Saarngam) is the Rainbow (Harivillu in Telugu meaning' the bow of LordHari(LordNaaraayana)). Theraindropsarethearrowsemanating from thatdivineatmosphericbow.His SwordisknownasNandakam, which means 'the one that causes Happiness and Prosperity', i.e., by sundering grief and sorrow, bestowing life-sustaining water in the form of rain. The Sun, who is the chief facilitator of this hydrological cycle, is called "Soorya Naaraayana"(or) "Pratyaksha Naaraayana" (visible Naaraayana). Raama, who is identified to be the personification of the Sun, is eulogized to be the incarnation of Lord Naaraayana.

Moreover, Naaraayana reclines amidst an endless ocean His serpent-bed. This also signifies the hydrological cycle as oceans are the crucial component and source of sustenance for the water cycle in many ways. In the divine Vishnu Sahasra Naamam, the Almighty has been described as 'Vaayu Vaahana', ie. 'The one who possesses wind (atmosphere) as his vehicle'. This applies to the Sun immediately because solar radiation and all other changes in the Sun are transmitted throughout the planet only by the atmosphere (winds). Hence, Lord Vishnu (the All-Pervading Almighty) can certainly be identified with the Sun as far as Earth and the entire solar system is concerned. Each and every atom in the whole solar system houses Sun's energy in some form or the other. The modern science also agreed upon this postulation. Hence, the qualities ascribed to Raama or Naaraayana can be attributed and related to the Sun and other atmospheric phenomena, like the hydrological cycle, etc. quite easily. Even Goddess Lakshmi, the eternal consort of Lord Naaraayana and the bestower of all sorts of wealth and prosperity on mankind, is also said to have evolved from the ocean. This entitlement predominantly projects the fact that water/rainfall (for which, oceans are the main source and force) is the principal cause of the existence, sustenance and prosperity of life in the world.

\subsection{Hanumaan and frames of reference}

Hence, just before the eclipse, there was a build-up of haze/dust storm/cumulonimbus clouds that dominated the effect of eclipse. Then the thunderstorm ensued, which is represented by Indra(rain, thunder and clouds) hitting Hanumaan with his fierce weapon (Vajraayudham) and Hanumaan falling down unconscious. This can be seen as the rapid down drafts of air in the cumulonimbus clouds when they rain. Later, Hanumaan obtained all the knowledge from the Sun, becoming his disciple. He stood facing the Sun by placing one leg on the Eastern Hills and another on the Western Hills. Needless to say, this is possible only for wind, which travels from East to West and is prevalent in between. Hanumaan learning everything from Sun by adjusting his alignment according to the Sun's positions during the day signifies the influence of Sun on winds. Winds are produced, controlled and circulated by Sun's radiation, as it causes pressure gradients, allowing air to flow from one region to another as blowing winds. Hanumaan standing in such a way (described above) that he always faces the Sun without having to move even an inch, explains a lot about the knowledge of our ancients pertaining to the relative motion of the Sun with respect to the earth's rotation and the so - called 'modern day physics concept' of 'inertial and non-inertial frames of reference'.

\subsection{Indrajit, Kumbhakarna, Vibheeshana and Mandodari}

Indrajit (original name Meghanaatha; meaning the 'controller of clouds') is the son of Raavana. 'Indrajit'means the 'one who conquered Indra' Generally Indra represents thunderclouds that produce beneficial rainfall. Hence, 'Indrajit' refers to an atmospheric condition where the clouds are allowed to neither shower rainfall nor clear the sky facilitating abundant Sunshine. 'Lakshmana', who is the brother of Raama, killed him. In other words, 'Lakshmana'is the personification of the 'Lakshana' (qualities) of Raama (Sun). This explains the phenomenon of Indrajit.

When Indrajit made Lakshmana unconscious by his astrams (divine arrows), it was Hanumaan who brought the Dronagiri 
Mountain that housed the Sanjeevini herb, from the Himalayas and saved the life of Lakshmana. Here, from the previous paragraph,Indrajit is the atmospheric condition that hindered the functioning of solar radiation and convection (Lakshmana) in the atmosphere, thereby creating an anti-cyclonic circulation (area of high pressure) and also inducing atmospheric inversion conditions, as already described. Then, the winds blowing from the northern part of India, carrying ample moisture pervaded the entire region, thereby saturating the air parcels over that region and counteracting the inversion mechanism. This activity of the moisture-laden northern mountain winds (Sanjeevini) brought about equilibrium in temperature and consequently pressure conditions, restoring normalcy in the dynamic processes of the atmosphere. Moreover, the name of the mountain is Dronagiri. As per the ancient Indian Meteorology, Drona is a class of clouds which resemble the shape of a pot or a trough. They rain incessantly and can be identified with the Cumulus class of clouds. Giri means 'Hill/Mountain'. Therefore, it can be presumed easily that the northern winds from the Himalayas brimming with moisture, capable of generating Drona type clouds (Cumulus clouds) have cleared the anti-cyclonic circulation prevalent over that region. The nomenclature Dronagiri also suggests that these winds are 'orographic' in nature. Besides, the word 'Sanjeevini' means 'the one which sustains or promotes life', which is readily synonymous to water. Hence, on the whole, Hanumaan (Synoptic Winds) transmitted the mountain/hill breezes (Dronagiri) containing lots of water vapour or moisture (Sanjeevini) to the South (Lanka), resulting in the refurbishment of normal atmospheric dynamics (bringing Lakshmana back to life). Kumbhakarna is the bother of Raavana. The word 'Kumbha' in Sanskrit means a pot / trough. The shape reminds us of a cumulonimbus cloud. Hence, Kumbhakarna is a dormant cumulonimbus cloud, which once triggered, causes havoc.

Vibheeshana is the youngest brother of Raavana. 'Vibheeshana'means 'not terrifying'/ 'not dreadful'. 'Vi' gives a negation and 'bheeshana' means 'terrifying'. Hence, Vibheeshana represents a group of relatively high altitude clouds that yielded beneficial and congenial rainfall, on coming into contact with Raama's (Sun's) atmospheric army. This can be understood by the episode of Vibheeshana seeking the asylum of Raama. 'Mandodari' is the wife of Raavana. 'Manda' represents earth / water and 'Udara' means 'stomach'. Mandodari represents a fertile land with abundant water resources. Mandodari represents a land with abundant rains and wet climate. Seetharepresents the Indian land with prevalent tropical climate. This is the reason why, in the Sundara Kaanda of the Raamaayana, Hanumaan mistook Mandodari for Seetha and later realized his folly.

\subsection{The Curse of Hanumaan}

In Raamaayana, Lord Hanumaan has a curse that he will not realise his powers unless he is remembered of them by someone. Air remains still and stable in the absence of any temperature and pressure variations. With the influence of increase temperature (Sun's heat), air parcels expand and rise up. In Raamaayana, Lord Hanumaan (wind) fetches his power from the chanting of the holy name 'Raama', by which he expands his body and takes off for a majestic flight on a purpose. This temperature rise creates a pressure gradient that makes the winds travel from one region to another. This insolation by the Sun's rays made the winds travel over the sea; capturing the moisture on their way that would induce the saturation of clouds, by making them rain. Sea surface is generally warmer than that of the land because the rate of absorption and rate of emission of heat from sea are slower than those of the land. Therefore, these hot sea breezes also tend to unsaturate the air parcels and dismantle the clouds. This is the significance of Raama's army crossing the sea by building a bridge made of rocks with the name of Raama written on each of them to keep them from drowning. When winds blow through a region of low temperature, then, the air parcels contract. Hence, Hanumaan (wind) shrinks his body as soon as he reaches Lanka (the region of dense groups of clouds). Sea surface temperature plays a key role in the onset and withdrawal of monsoon winds and in the formulation of various weather prediction models such as power regression model and others. Variations in sea surface temperature also generate El Nino (Warming) and La Nino (Cooling) conditions, which command a crucial role in determining the global climatic scenario.

\subsection{The Annihilation of Raavana}

Raavana was engaged in a fierce battle with Raama. Despite the repeated severing of his heads by Raama's arrows, they were restored. Then, going by the suggestion of Vibheeshana to strike Raavana in the abdomen where there was a pot of nectar (AmrutaBhandam), Raama kills Raavana finally. We have already seen that the ten heads of Raavana have been attributed to the sound of thunder made by the dense clouds. Initially, despite changes in temperature and advent of winds, the dense clouds in the form of Raavana were weakened, but restored within no time. The 'nectar' in a cloud is the symbolism for moisture/rainwater, because it sustains all forms of life on the earth. Hence, the cloud is prone to un-saturation if it is devoid of water literally or is subjected to accelerated saturation which drains it by making it rain. This explains the killing of Raavana by Raama, suitably. Further, Raama got the better of Raavana in the epic battle with the help of Vibheeshana's advice. We have already seen that Vibheeshana represents a group of beneficial and relatively high-altitude clouds. In the atmosphere, sometimes, the higher clouds like cirro form clouds and 
alto form clouds provide the required condensation nuclei for low-lying cumuliform and strato clouds; thereby facilitating 'Cloud seeding' and making them rain or disperse, clearing the sky. The transfer of moisture, ice crystals, cloud droplets, etc. from the upper clouds to the lower clouds is aided by air. The saturated air parcels, which are unable to hold the cloudlets aloft, transfer them to the lower clouds, initiating the above stated mechanism. This explains the cordial relation of Vibheeshana (Clouds) with Hanumaan (Air), who, in turn is commissioned by Raama (Sun), as temperature plays a pivotal role in the saturation and unsaturation of air parcels. In addition to this, the epic also describes that the war between Indrajit and Lakshmana as well as that between Raama and Raavana was "fought in the Sky", fortifying the proposition that it has all the attributes of an 'Atmospheric War'. From all these, we can state convincingly that the Raamaayana war is not only a 'Climactic Battle', but also a 'Climatic Battle'.

\section{Conclusion}

Vaalmeeki's Raamaayana fits into any branch of discipline of Science, Arts, Philosophy and Spirituality effectively, as opined by scholars. However, I think; more than any other science, Meteorology is just tailor-made to fit into this epic's versatile garment. In this way, the concepts of science have been encrypted in our Vedas, Puraanas, Epics and Classics. They occur as intermittent and proxy references in many of them. Only a well-versed Sanskrit scholar-cum-a Scientist would identify and analyse them. For others, they remain some divine and spiritual dramatic narrations. This shortfall prompted the post-Vedic scholars to try and bring out some exclusive treatises on Sciences or the ones dedicated to a particular topic like Economics, Politics, Management, Administration, etc. Brihat Samhita of Varaaha Mihira is one such encyclopedic masterpiece (Rama Krishna Bhat, 1981).

In this epic, Lord Hanumaan was the one who facilitated the union of Raama and Seetha. Lord Hanumaan being the personification of Air/Wind (Atmosphere) which lies in between the earth's surface and the solar radiation, this entitlement in the Raamaayana could be considered stupendous. Hanumaan, who is the atmospheric link between the Sun and the Earth, travelling over the ocean from Raama to Seetha and back to Raama (from atmosphere to the Earth and from the Earth, back to the atmosphere) depicts the phenomenon of hydrological cycle that involves insolation (Hanumaan travelling from Raama to Seetha over the ocean as the oceans are the primary source of rainfall, providing the required water vapour and moisture for precipitation. Here, the atmosphere transfers the Sun's heat to the earth) and evaporation (back from Seetha to Raama, again across the ocean). Hence, clearly, this is the concept of water cycle explained here in disguise. This voyage of Hanumaan across the ocean and the battle that ensued was an attempt to clear the dense clouds (Raavana), by condensing them and making them rain. This would also lead to the prosperity of the region owing to the copious rainfall. This would pave the way for the restoration of normalcy pertaining to the weather conditions over the land.

The very word Viswaamitra points to the Sun as Mitra is synonymous to Sun in Vedas and other Indian texts. The word 'Viswam' means 'Universe'. Hence, Viswaamitra signifies that very beneficial and life-sustaining qualities of the Sun, prevalent universally in each and every star like our Sun. Now, one can grasp the logic behind the fact that Raama, who is the manifestation of our own Sun is the disciple of Viswaamitra and was guided by the sage to marry Seetha, the Earth (Indian Land), during the course of which he encountered the episodes of Taataka, Ahalya and others. Raama was followed by Lakshmana (He is the manifestation of the qualities (Lakshanas) of the Sun, as stated earlier). As one's own qualities never desert him (Avinaa bhaava sambandham), Lakshmana always accompanied Raama, throughout the epic. It is hard to find an instance, where Raama was left all alone in accomplishing a task. The other brothers of Raama also are nothing but his own characteristics. Bha means 'Light' and Rata means 'to merge or rejoice'. Hence, the word 'Bharata' means 'the one who merges/rejoices in light/brightness/radiance', which is a virtue of the Sun. Similarly, Shatru means 'enemy or foe' and Ghna stands for 'destruction or annihilation'. Shatrughna means the one who destroys his enemies. In Aaditya Hrudayam of the Raamaayana, the Sun is described as 'Shatrughna'.

\section{"TamoghnaayaHimaghnaayaShatrughnaayaAmitaatmane KrutaghnaghnaayaDevaayaJyotishaamPatayeNamaha”(AadityaHrudayam, Slokam20)}

Here, the Sun is described as the described the destroyer of darkness (also the darkness of ignorance), destroyer of snow (himam) and the destroyer of all the enemies (shatru); whether they may be the internal enemies in the hearts of the mankind or the inclement atmospheric conditions, as in the Raamaayana. That is why Naaraayana (Sun is also called 'Soorya Naaraayana') is eulogized as "Srushti-Sthiti-Laya Kaaraka” meaning 'the cause of creation, sustenance and dissolution'. The Aaditya Hrudayam also attributes the same quality to the Sun by proclaiming thus:

\section{"Naasayatyesha vai Bhutam Tadeva Srujati Prabhuhu...........” (Aaditya Hrudayam, Slokam 22)}

This means 'the Lord who dissolves everything and re-creates the same from Him'. This proves that the entire story of Raamaayana revolves around Raama (Sun) as the Earth revolves around the Sun. 
In this way, ancient Indian seers and sages observed the drastic and dynamic weather phenomena with awe and admiration. They described and documented their observations alongside the main storyline of the epics and classics. However, Raamaayana stands out as an excellent example for atmospheric science embedded into a dramatic narrative. This fills our hearts with adoration and veneration towards Sage Vaalmeeki who encoded intricate sciences, enveloped into the epic, especially meteorology. He thus commands a unique position beside the greatest scientists of the ancient and the modern times as well. The concepts presented in the present article are only like the 'tip of the ice berg'. An intensive and an all-inclusive in-depth study of the Raamaayana would certainly unravel more and more concealed as well as disguised scientific concepts.

In the Vedas, the waters have been acclaimed to be 'Jagat Bhagini' (Sister of the Universe). Jagat means 'Universe' and Bhagini means 'Sister'. This means the universe and water are interrelated. Rigveda says that there were primordial indistinguishable waters (Naara/Salilam) at the beginning, from which the entire creation had sprung up. This nomenclature of Jagat Bhagini also tells us that water is the principal cause for the prosperity and well-being of the universe. Therefore, there are no prizes for guessing why atmospheric science has been ordained with utmost significance among all the ancient Indian sciences. To conclude, the immediate need and demand of the hour is to extract and integrate ancient atmospheric science imbedded into various Indian texts like the Raamaayana, Brihat Samhita, Meghamaala Manjari, etc., with the modern meteorological dexterity to arrive at a comprehensive, conclusive and a thoroughly reliable weather forecast system in the near imminent future.

\section{Acknowledgement}

My reverential salutations to Sage Vaalmeeki for composing the ever green masterful epic Raamaayana, which enshrines many scientific, social, spiritual, mystic and ethical principles. My deep gratitude to my mother Dr. V. Parvathi Devi, for typesetting and formatting the article. My affectionate thankfulness to my father Dr. K. Ramamoorthy, for some fruitful and enlightening discussions on the subject. I extend my warm regards to my research supervisor Prof. M. Krishnaiah for encouraging me to take up such works relating ancient Indian Scientific Principles to Contemporary Scientific Achievements. Last, but, never the least; I express my heartfelt gratefulness and appreciation to Ms. Hari Priya Chinthapally, USA for her valuable feedback pertaining to several aspects of this article.

\section{References}

1 Aaditya Hrudayam; Published by Raama Krishna Math, Hyderabad, XIV-6M-2-2009, 2009.

2- Rama Krishna Bhat, M., Varaaha Mihira's Brihat Samhita (Text with Translation), Motilal Banarsidass Publishers Private Limited, New Delhi (1981)

3• Ramanathan, A.S. (1991); Introduction to 'Kaadambini' by Sri Madhusudan Ojha translated by Pradyumna Ojha, (Harimohan Printing Press, Jaipur), pp. 1-44.

4- Uma Shankar Dubey (1989), "Praacheena Varsha Vignyana”, Sri HanumatJ yotish Mandir, Jaipur City, pp : 1-180.

5- Vanadeep K, Sada Siva Murty R and Krishnaiah M (2012); Meticulous and Meritorious Meteorology Enshrined in the Brihat Samhita - A Comparative Case Study over Four Indian Regions Situated in Diverse Climatic Zones, Indian Journal of Innovations and Developments. Vol. 1, No.4, pp. $229-290$. 